\title{
Evaluation of the efficacy of two doses of vitamin D supplementation on glycemic, lipidemic and oxidative stress biomarkers during pregnancy: a randomized clinical trial
}

Soudabe Motamed ${ }^{1}$, Bahareh Nikooyeh², Maryam Kashanian ${ }^{3}$, Maryam Chamani ${ }^{3}$, Bruce W. Hollis ${ }^{4}$ and Tirang R. Neyestani $2^{2^{*}}$ (D)

\begin{abstract}
Background: Vitamin D deficiency during pregnancy is common and is likely to be associated with metabolic complications in the mother. The aim of this study was to assess the efficacy of two doses of vitamin D supplementation during pregnancy on maternal and cord blood vitamin D status and metabolic and oxidative stress biomarkers.

Methods: The eligible pregnant women $(n=84)$ invited to participate in the study and randomly allocated to one of the two supplementation groups (1000 IU/d vitamin D and $2000 \mathrm{IJ} / \mathrm{d})$.

Biochemical assessments of mothers including serum concentrations of $25(\mathrm{OH}) \mathrm{D}$, calcium, phosphate, iPTH, fasting serum sugar (FBS), insulin, triglyceride, total cholesterol, LDL-C, HDL-C, malondialdehyde (MDA) and total antioxidant capacity (TAC) were done at the beginning and 34 weeks of gestation. Cord blood serum concentrations of 25(OH)D, IPTH, MDA and TAC were assessed at delivery as well. To determine the effects of vitamin D supplementation on metabolic markers 1-factor repeated-measures analysis of variance (ANOVA) was used. Between groups comparisons was done by using Independentsamples Student's t-test or Mann-Whitney test. $P<0.05$ was considered as significant.

Results: Supplementation with $1000 \mathrm{IJ} / \mathrm{d}$ and $2000 \mathrm{IU} / \mathrm{d}$ vitamin D resulted in significant changes in vitamin D status over pregnancy (24.01 $\pm 21.7, P<0.001$ in $1000 \mathrm{IU} / \mathrm{d}$ group and $46.7 \pm 30.6 \mathrm{nmol} / \mathrm{L}, P<0.001 \mathrm{in} 2000 \mathrm{IU} / \mathrm{d}$ group). Daily intake of 2000 compared with $1000 \mathrm{IU} / \mathrm{d}$ tended to increase the serum concentration of $\mathrm{HDL}-\mathrm{C}(10 \pm 8.37, P<0.001 \mathrm{in} 1000 \mathrm{IU} / \mathrm{d}$ group and $9.52 \pm 11.39 \mathrm{mg} / \mathrm{dL}, P<0.001$ in $2000 \mathrm{IU} / \mathrm{d}$ group). A significant decrement in serum concentration of iPTH observed in both groups ( $-4.18 \pm 7.5, P=0.002$ in $1000 \mathrm{IU} / \mathrm{d}$ group and $-8.36 \pm 14.17, P=0.002$ in $2000 \mathrm{IU} / \mathrm{d}$ group).
\end{abstract}

Conclusions: Supplementation with $2000 \mathrm{IU} / \mathrm{d}$ vitamin D as compared with $1000 \mathrm{IJ} / \mathrm{d}$, is more effective in promoting vitamin D status and HDL-C serum concentration and in decreasing IPTH over pregnancy.

(Continued on next page)

\footnotetext{
* Correspondence: t.neyestani@sbmu.ac.ir; neytr@yahoo.com

¿2Laboratory of Nutrition Research, National Nutrition and Food Technology Research Institute and Faculty of Nutrition Sciences and Food Technology, Shahid Beheshti University of Medical Sciences, Hafezi St., Farahzadi Blvd., Shahrak Qods (Gharb), Tehran 1981619573, Iran

Full list of author information is available at the end of the article
}

C C The Author(s). 2020 Open Access This article is licensed under a Creative Commons Attribution 4.0 International License, which permits use, sharing, adaptation, distribution and reproduction in any medium or format, as long as you give appropriate credit to the original author(s) and the source, provide a link to the Creative Commons licence, and indicate if changes were made. The images or other third party material in this article are included in the article's Creative Commons licence, unless indicated otherwise in a credit line to the material. If material is not included in the article's Creative Commons licence and your intended use is not permitted by statutory regulation or exceeds the permitted use, you will need to obtain permission directly from the copyright holder. To view a copy of this licence, visit http://creativecommons.org/licenses/by/4.0/. The Creative Commons Public Domain Dedication waiver (http://creativecommons.org/publicdomain/zero/1.0/) applies to the data made available in this article, unless otherwise stated in a credit line to the data. 
(Continued from previous page)

Trial registration: This trial is registered at clinicaltrials.gov (NCT03308487). Registered 12 October 2017 'retrospectively registered'.

Keywords: Vitamin D supplementation, Pregnancy, Glycemic status; lipid profile

\section{Background}

Physiologic alterations during pregnancy cause changes in the concentrations of many circulating metabolites and analytes including glucose, lipids and lipoproteins. The extent of these changes highly depends on interactions of dietary intake, genetic makeup and hormonal milieu [1-3].

Among the modifiable factors affecting gestational blood glucose and lipid alterations, nutrition has a crucial role. Apart from proper gestational weight gain and adhering to a healthy diet prior to and throughout pregnancy, vitamin $\mathrm{D}$ status of mother has attracted a huge attention for some reasons [4, 5]. Several research groups have scrutinized the relationship between vitamin D deficiency and abnormal glucose homeostasis [6-10] and lipid metabolism [11] in pregnancy. Furthermore, some clinical trials have revealed that vitamin D supplementation during pregnancy might improve the status of lipid profile [12-14], glycemia [15], and parathyroid hormone [16].

It is believed that certain level of oxidative stress (OS), both placental and maternal, is necessary for a normal pregnancy $[17,18]$. However, pathological increment of OS during pregnancy could have a role in development of adverse pregnancy outcomes through damaging susceptible placenta $[19,20]$. On the other hand, some studies have revealed antioxidative properties of vitamin D [21-23] which might be associated with certain metabolic variables, notably blood glucose and lipids [24]. However, these effects of vitamin D during pregnancy still need further elucidation.

High prevalence of vitamin D deficiency during pregnancy is common in most countries of the world [25, 26], including Iran [27, 28]. It is noteworthy that the Iran Ministry of Health (IrMOH) communicated with all governmental health centers to prescribe $1000 \mathrm{IU} / \mathrm{d}$ vitamin D supplement to all pregnant women from the beginning of pregnancy. However, the efficacy of supplementation with this dosage (1000 IU/d) early in pregnancy has not yet been evaluated and compared with that of $2000 \mathrm{IU} / \mathrm{d}$, which has been more efficient in improving vitamin D status and depressing certain inflammatory biomarkers, than $1000 \mathrm{IU} / \mathrm{d}$ [29]. We, therefore, designed this clinical trial from the first trimester of pregnancy to examine and compare the efficacy of these two dosages of vitamin D (1000 IU/d and $2000 \mathrm{IU} / \mathrm{d})$ on certain metabolic parameters including glycemic, lipidemic and parathyroid hormone as well as OS status.

\section{Methods \\ Study design}

This study was a part of a larger project whose complete protocol has been comprehensively described elsewhere [30]. In an open-label randomized clinical trial, 84 pregnant women who met the inclusion criteria and were attending the outpatient obstetric clinics of three hospitals (with similar cultural, educational and economic status) in Tehran between February 2017 and January 2018 were enrolled. This study adhered to CONSORT guidelines.

We calculated that a sample of 37 subjects in each group would have $90 \%$ power to detect a change in means of 25(OH)D of 0.75 of SD (assuming an effect size of 0.75). Based on the previous study [31], 0.75 of SD would be $18 \mathrm{nmol} / \mathrm{L}$.

Inclusion criteria were: 1 ) being at the first trimester of pregnancy, 2) the absence of any clinical disease including endocrine, cardiovascular, liver and kidney diseases, 3) not taking vitamin D (>600 IU/d) and/or omega- 3 supplements and/or steroids during the past 3 months, 4) the willingness to take part in the study.

Exclusion criteria were: 1 ) identified to have FBS $>92$ $\mathrm{mg} / \mathrm{dL}$ or blood pressure $>140 / 90 \mathrm{mmHg}$ at the first visit, 2) consuming omega-3 and/or extra vitamin D supplement and/or other drugs that interfere with vitamin $\mathrm{D}$ metabolism during the intervention period, 3) poor compliance to the supplementation 4) unwillingness to continue the intervention.

Those subjects who met the inclusion criteria were randomly allocated to one of the two groups to take either $1000 \mathrm{IU}$ (one tablet)/d or $2000 \mathrm{IU}$ (two tablets)/d vitamin $\mathrm{D}$ from the first trimester till the end of pregnancy. Block randomization applied using 6 blocked sizes of 4 to generate 21 randomized block allocations for random allocation. All participants were allowed to receive the common supplementation during pregnancy (folic acid, iron and multivitamins providing $<600 \mathrm{IU} / \mathrm{d}$ vitamin D). The vitamin D3 tablets were purchased from Jalinous pharmaceutical company, Tehran, Iran.

All subjects were visited at first trimester and 34-36 week of gestation. At the first visit, demographic information was collected from all participants. Adherence to the determined supplementation regimen was evaluated as described earlier [30]. Briefly, the participants were asked to return the pills not consumed for any reason. Meanwhile, they were contacted by telephone call every week to check consumption of the supplements. The 
following equation was applied to assess the adherence rate: (Number of pills dispensed - number of pills remained)/(prescribed number of pills per day $\times$ number of days between 2 visits. Accordingly, the participants divided into three groups including strictly $(>=80 \%)$, moderately $(50-80 \%)$ and poorly $(\leq 50 \%)$ compliant. Those participants with poor compliance (consumption of less than $50 \%$ of the prescribed vitamin D supplements in a month) were excluded from the study. The strictly and moderately compliant subgroups supposed to be separately analyzed.

Anthropometric and blood pressure measurements have been described elsewhere [30].

To determine the mean score of sunlight exposure, the information about the amount of time spent outdoors each day during previous week were collected by using the weekly sunlight exposure recall questionnaire [32]. Then the score of time outdoors (score 0 for $\leq 5 \mathrm{~min}$; score 1 for 5-30 min; score 2 for $\geq 30 \mathrm{~min}$ ) and the score of the amount of skin exposure (score 1 for face and hands only; score 2 for face, hands, and arms; score 3 for face, hands, and legs; score 4 for almost the entire body) were multiplied to calculate sunlight exposure score. The sunlight exposure score range is assumed to be 0 to 56 [32].

To assess the level of physical activity, an Iranian version of the International Physical Activity Questionnaire (IPAQ) was used [33].

A 24-h recall questionnaire was used to assess the amount of energy, macronutrient (protein, carbohydrate and fat) and micronutrient intake (vitamin A, D, E, K, C, calcium, iron, zinc) for 2 days (a week day and a weekend day), the mean of which was considered as the individual's dietary intake. The analysis of questionnaires data was done using Nutritionist IV software (First Databank, San Bruno, CA, USA) modified for Iranian foods.

The protocol of this study was approved by the Ethics Committee of Shahid Beheshti University of Medical Sciences. This trial is registered at clinicaltrials.gov (NCT03308487).

\section{Biochemical investigations}

Ten $\mathrm{mL}$ of $12-14 \mathrm{~h}$ fasting venous blood and spot urine samples were collected from all participants at first trimester and 34-36 weeks of gestation. In addition, $5 \mathrm{~mL}$ of cord blood samples were collected at the time of delivery. All blood and urine samples were transferred to the Laboratory of Nutrition Research, NNFTRI, in a cold box. Blood samples were centrifuged in less than $2 \mathrm{~h}$ at $800 \mathrm{~g}$ at room temperature for $30 \mathrm{~min}$. The separated sera and urine samples were aliquoted and kept at $80^{\circ} \mathrm{C}$ freezer for further analyses. Sera from cord blood samples were handled similarly.

Fasting serum glucose, lipid profile components, calcium and phosphorous were assayed on the same day of blood sampling using commercial kits (all from ParsAzmoon, Tehran, Iran) and an auto-analyzer (Selecta E; Vitalab, Holliston, Netherlands).

Fasting serum insulin was measured by using an enzyme immunoassay (EIA) kit (DiaPlus inc., Canada) with intra- and inter-assay coefficient of variations (CVs) of 4.9 and $8 \%$, respectively, based on manufacturer's data.

HOMA-IR which calculated based on suggested formulas [34], was used to assess insulin resistance.

The concentrations of $25(\mathrm{OH}) \mathrm{D}$ and $\mathrm{iPTH}$ in all serum samples were determined using commercial enzyme-immunoassay (EIA) kits (both from EUROIMMUN, Leubeck, Germany). For 25(OH)D assay kit, the inter-assay CVs ranged from 7 to 8.6- and intra-assay CVs ranged from 3.2 to $6.9 \%$ whereas for iPTH intraand inter-assay CVs were $2.2-9.5 \%$ and $9.5-11 \%$, respectively, according to the manufacturer.

Urinary calcium and creatinine concentrations were measured by commercial kits and an auto-analyzer. The proportion of urinary calcium to creatinine concentrations in the spot urine samples was used to determine the possible effects of vitamin D supplementation on urinary calcium excretion.

To evaluate OS, serum concentrations of malondialdehyde (MDA) as well as total antioxidant capacity were determined. MDA assay was performed using thiobarbituric acid reacting substances (TBARS), as previously described [29]. To determine total antioxidant capacity (TAC), the ability of serum antioxidants to inhibit $2,2^{\prime}$ azino di-(3-ethylbenzthiazoline sulfonate; ABTS) oxidation was compared with that of bovine serum albumin, as the standard [35].

\section{Statistical analysis}

To check normal distribution of continuous variables the histogram and Kolmogorov-Smirnov test were applied.

The continuous data which normally distributed shown as mean and standard deviation (SD) and categorical data presented as frequency or percentage (\%). Repeatedmeasures ANOVA was used to determine the effect of vitamin D supplementation on metabolic markers. In this analysis, the treatment $(2000 \mathrm{IU} / \mathrm{d}$ vitamin D vs. $1000 \mathrm{IU} / \mathrm{d}$ vitamin $\mathrm{D}$ ) and time (with 2 time points including baseline and week 34 of the intervention) were considered as "between-subject factor" and "within-subject factor" respectively. For between groups comparison, Independentsamples Student's $t$-test or Mann-Whitney test was used. Either Pearson $(r)$ or Spearman $\left(r_{s}\right)$ equations were applied to assess the correlations between variables. The significant level was $P<0.05$.

\section{Results}

A total of 84 pregnant women were enrolled in the study between February and June 2017. However, 73 subjects 
( $n=37$ from group $1000 \mathrm{IU} / \mathrm{d}$ and $n=36$ from group $2000 \mathrm{IU} / \mathrm{d}$ ) completed the intervention. Losses and exclusions were due to some reasons including miscarriage, preterm delivery, and unwillingness to continue the participation (Fig. 1). Follow up period lasted till January 2018.

In this study 2 subjects (about 5\%) from $2000 \mathrm{IU} / \mathrm{d}$ group had poor compliance and were excluded from the study. The mean adherence percent among those who continued the study were 93.7 and $90.4 \%$ in $1000 \mathrm{IU} / \mathrm{d}$ and $2000 \mathrm{IU} / \mathrm{d}$ groups respectively. It is necessary to mention that all participants who completed the study were belonged to the strictly compliant subgroup. Therefore, the study was out of moderately compliant subgroup.

The baseline characteristics, sun exposure score and physical activity level of the participants, duration of intervention, number (percent) of participants who have received routine supplementation and season of year at the first visit have been shown in Table 1.

Vitamin D deficiency/insufficiency was found in 83.8 and $86.2 \%$ of the subjects in $1000 \mathrm{IU} / \mathrm{d}$ group and 2000 IU/d groups, respectively (Table 3 ).

The increment of the $25(\mathrm{OH}) \mathrm{D}$ was significantly higher in response to vitamin $\mathrm{D}$ supplementation with the dose of $2000 \mathrm{IU} / \mathrm{d}$ compared with $1000 \mathrm{IU} / \mathrm{d}$ (Tables 2 and 3). No significant between groups difference was found in the cord blood concentration of $25(\mathrm{OH}) \mathrm{D}$ (Table 4). The cord blood serum concentrations of $25(\mathrm{OH}) \mathrm{D}$ had a significant positive correlation with the maternal one at third trimester $(r=0.38, P=0.02)$.

Within- or between-group changes of FBS, serum insulin, HOMA-IR were not significant. Compared with the baseline values the concentration of TC, TG, LDL-C and HDL-C increased significantly in both groups. However, between group changes were not significant (Table 2). A small but statistically significant decrease in serum calcium concentrations at late pregnancy was observed in both groups $(P<0.001)$, although the values remained in normal range. However the between-group difference was not significant $(P$-interaction $=0.51)$. Serum phosphate concentration did not differ over pregnancy in both groups $(P$-interaction $=0.21)$.

Final serum concentrations of iPTH in both groups decreased late in pregnancy $(P<0.05)$ but the difference between groups was not significant (Table 2). The cord blood concentration of iPTH was not significantly different between groups, either (Table 4). A significant negative correlation was found between serum concentrations of $25(\mathrm{OH}) \mathrm{D}$ and iPTH $(r=-0.35, P=0.003)$. The correlation between mothers' and cord blood serum concentration of iPTH was not significant $(r=0.19, P=0.32)$.

The biomarkers of OS (MDA and TAC) did not change significantly over pregnancy in any of the groups
(Table 2). Accordingly, cord blood MDA and TAC did not show any significant between-group changes, either (Table 4).

Initial and final dietary data showed no significant between group differences (Table 5).

\section{Discussion}

We found a relatively high proportion of vitamin D deficiency and insufficiency among study participants at first trimester of pregnancy. This finding is consistent with what has been reported by several studies about the percentage of vitamin D deficiency among Iranian pregnant women [27].

In addition, taking $2000 \mathrm{IU} / \mathrm{d}$ vitamin $\mathrm{D}_{3}$ for 24 weeks improved vitamin $\mathrm{D}$ status more effectively than taking $1000 \mathrm{IU} / \mathrm{d}$. This finding was compatible with that of other trials examined the efficacy of similar doses [37-39].

Sufficient concentrations of cord blood 25(OH)D (> 75 $\mathrm{nmol} / \mathrm{L}$ ) were observed in both groups with no significant between-group difference. Along the same line of evidence, the daily intake of 2000-4000 IU vitamin $\mathrm{D}_{3}$ among women from 12 to 16- weeks of gestation until delivery prevented neonatal vitamin D deficiency [40].

Our study showed no association between vitamin $\mathrm{D}$ supplementation and parameters of glucose homeostasis including FBS, insulin and HOMA-IR during pregnancy. In agreement with our findings, some studies failed to show any beneficial effects of vitamin D supplementation on glycemic status of pregnant women [7, 8, 41, 42]. The results of some cohort studies showed that the concentrations of circulating $25(\mathrm{OH}) \mathrm{D}$ might not be a contributing factor for development of GDM in women with a low risk for GDM $[9,43]$. On the contrary, the results of a clinical trial showed that co-administration of $1000 \mathrm{mg}$ calcium per day $+50,000 \mathrm{IU}$ vitamin D every 3 weeks for 6 weeks to pregnant women with GDM could improve glycemic status [44]. The effect of vitamin D supplementation on glycemic status has been attributed to its involvement in insulin secretion through its effect on the regulation of serum calcium which in turn affects pancreatic $\beta$ cell function [45]. The observed inconsistency might be due to the differences in doses and duration of vitamin $\mathrm{D}$ supplementation and the lack of calcium co-supplementation and the fact that in our study, vitamin $\mathrm{D}_{3}$ was administered to healthy pregnant women with normal values of glycemic status.

We found a significant increase in serum concentrations of lipid profile components including TG, total cholesterol, HDL-C and LDL-C from beginning to the late pregnancy in both groups, but the differences were not significant between groups. During pregnancy along with increasing gestational age the levels of lipid profile increase most probably due to hormonal and metabolic changes as a normal physiologic phenomena [46-49]. 


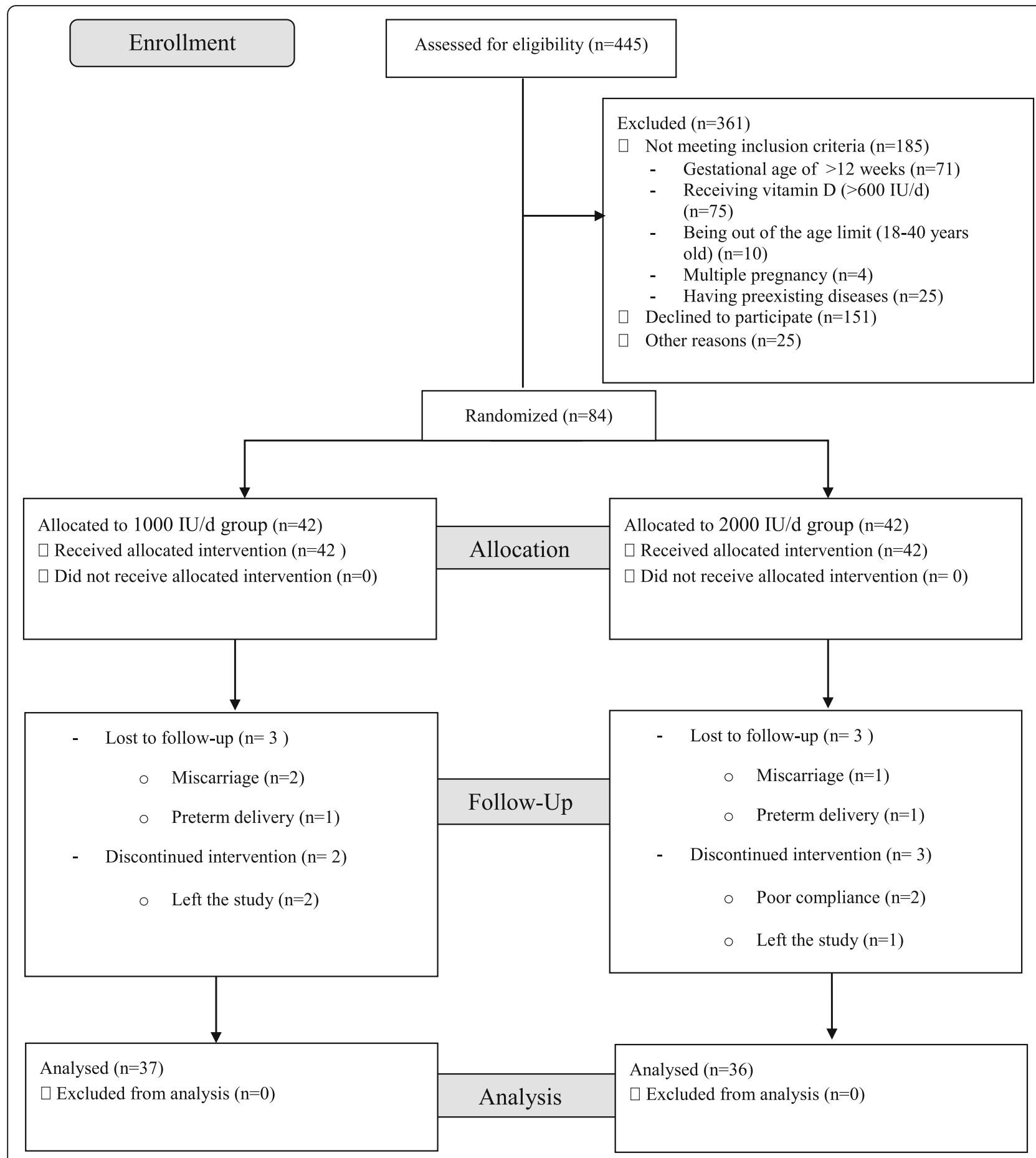

Fig. 1 Flow diagram of the study

The normal ranges of TG, TC, LDL-C, HDL-C during third trimester of pregnancy suggested to be 131-453, $219-349,101-224$ and $48-87 \mathrm{mg} / \mathrm{dL}$ respectively [5052]. Nevertheless, the importance of changes of blood lipid metabolism during pregnancy pertains to its potential effect on perinatal morbidity and mortality. It has been reported that dyslipidemia in pregnancy associated with preeclampsia, GDM, preterm delivery and cardiovascular disease in the future [47]. Based on some evidence, vitamin $\mathrm{D}$ deficiency during early pregnancy associated with more unfavorable changes of lipid profile $[53,54]$. Therefore, it is assumed that vitamin D correction could have a beneficial effect on lipids during pregnancy. Asemi, et al. conducted a randomized, double- 
Table 1 Baseline characteristics of subjects ${ }^{\mathrm{a}}$

\begin{tabular}{|c|c|c|c|}
\hline Characteristic & $\begin{array}{l}\text { Group } 1(1000 \mathrm{IU} / \mathrm{d}) \\
\mathrm{n}_{1}=37\end{array}$ & $\begin{array}{l}\text { Group } 2(2000 \mathrm{IU} / \mathrm{d}) \\
\mathrm{n}_{2}=36\end{array}$ & $p$ value $^{2}$ \\
\hline Age, year & $27.94 \pm 5.60$ & $27.41 \pm 5.15$ & 0.80 \\
\hline Gestational age at enrollment, week & $10.39 \pm 1.69$ & $10.08 \pm 2.17$ & 0.77 \\
\hline Gestational age at delivery (week) & $38.79 \pm 1.65$ & $39.91 \pm 5.78$ & 0.57 \\
\hline Weight gain at end of pregnancy $(\mathrm{kg})$ & $10.82 \pm 5.21$ & $12.01 \pm 5.94$ & 0.38 \\
\hline Weekly sunlight exposure score at enrollment & $2.63 \pm 2.08$ & $1.97 \pm 1.67$ & 0.14 \\
\hline Weekly sunlight exposure score at last visit & $1.70 \pm 1.65$ & $1.21 \pm 1.15$ & 0.17 \\
\hline Sunscreen use, $n(\%)$ & $11(30.4)$ & $13(36.9)$ & 0.49 \\
\hline Physical activity at enrollment, $\mathrm{n}(\%)$ & & & 0.37 \\
\hline Low & $29(78.4)$ & $28(77.8)$ & \\
\hline Moderate & $8(21.6)$ & $6(16.7($ & \\
\hline High & $0(0.0)$ & $2(5.6)$ & \\
\hline Physical activity at last visit, $\mathrm{n}(\%)$ & & & 0.59 \\
\hline Low & $32(86.5)$ & $29(80.6)$ & \\
\hline Moderate & $5(13.5)$ & $6(16.7)$ & \\
\hline High & $0(0.0)$ & $1(2.8)$ & \\
\hline Duration of intervention, $\mathrm{n}(\%)$ & & & 0.87 \\
\hline $24 w k$ & $11(29.72)$ & $10(27.77)$ & \\
\hline $25 w k$ & $9(24.32)$ & $11(30.55)$ & \\
\hline $26 w k$ & $6(16.21)$ & $7(19.44)$ & \\
\hline $27 w k$ & $7(18.91)$ & $5(13.88)$ & \\
\hline $28 w k$ & $4(10.81)$ & $3(8.33)$ & \\
\hline Season at first visit, $n(\%)$ & & & 0.89 \\
\hline Winter & $14(37.6)$ & $16(44.4)$ & \\
\hline Spring & $23(62.1)$ & $20(55.5)$ & \\
\hline \multicolumn{4}{|l|}{ Routine supplementation ${ }^{\mathrm{a}}, \mathrm{n}(\%)$} \\
\hline Multivitamin & $25(67.5)$ & $22(61.1)$ & 0.52 \\
\hline Folic acid & $29(78.37)$ & $25(69.44)$ & 0.37 \\
\hline Iron & $21(56.75)$ & $22(61.11)$ & 0.55 \\
\hline
\end{tabular}

adata are expressed as mean \pm SD and the distribution between groups expressed as $n$ (\%)

${ }^{2} t$ test and $X 2$ test were used to compare baseline characteristics

$B M I$ Body mass index

${ }^{\text {a }}$ The participants started to intake routine supplementation late in the fourth month of pregnancy

blind, placebo-controlled clinical trial in 57 women with GDM that received 50,000 IU vitamin D at baseline and at day 21 of the intervention and those in the placebo group received 2 placebos at the same times. Based on the results, vitamin D supplementation resulted in increased serum 25-hydroxyvitamin D concentrations compared with placebo and a significant reduction in concentrations of total cholesterol and LDL-C [55]. In another study, supplementation of vitamin D among GDM cases showed no positive effect on lipid profiles compared with placebo. Although, serum concentration of total cholesterol and LDL-C had a significant increment in the placebo group [56]. Inconsistently, the results of a trial among pregnant women, who were prone to pre-eclampsia, revealed that supplementation of 50 , 000 IU vitamin D, every 2 weeks from gestational age of 20 to 32 weeks, in comparison to placebo, associated with increased level of HDL-C concentrations [57]. The possible effect of vitamin D on lipid metabolism could be in part explained by decreased synthesis and secretion of TG in liver and also transformation of cholesterol into bile acids and subsequently reduced level of cholesterol [58].

In the present study due to the lack of control group we were unable to detect the effect of vitamin D supplementation on the lipid profile. However, we found that the effect of vitamin D supplementation with two doses of $1000 \mathrm{IU} / \mathrm{d}$ and $2000 \mathrm{IU} / \mathrm{d}$ on the lipid profile during 
Table 2 Comparison of changes in variables within and between groups after the intervention ${ }^{\mathrm{a}}$

\begin{tabular}{|c|c|c|c|c|c|c|c|c|c|}
\hline \multirow[t]{2}{*}{$\begin{array}{l}\text { Group } \\
\text { Variable }\end{array}$} & \multicolumn{3}{|c|}{$\begin{array}{l}1000 \mathrm{IU} / \mathrm{d} \text { group } \\
n=37\end{array}$} & \multicolumn{3}{|c|}{$\begin{array}{l}2000 \text { IU/d group } \\
n=36\end{array}$} & \multicolumn{3}{|c|}{$p$ value $^{2}$} \\
\hline & before & after & changes & before & after & changes & Time & Group & $\begin{array}{l}\text { Time } \times \\
\text { group }^{\mathrm{b}}\end{array}$ \\
\hline $\begin{array}{l}\text { 25(OH)D3 }(\mathrm{nmol} / \\
\text { liter) }\end{array}$ & $45.32 \pm 29.70$ & $71.19 \pm 23.65^{*}$ & $24.01 \pm 21.7$ & $\begin{array}{l}47.03 \pm \\
31.70\end{array}$ & $\begin{array}{l}91.82 \pm \\
28.81^{*}\end{array}$ & $\begin{array}{l}46.7 \pm 30.6 \\
* *\end{array}$ & $\begin{array}{l}< \\
0.001\end{array}$ & 0.06 & 0.004 \\
\hline FBS $(\mathrm{mg} / \mathrm{dl})$ & $74.70 \pm 7.51$ & $75.59 \pm 6.98$ & $0.89 \pm 11.06$ & 78.41 & 77.55 & $-0.86 \pm 10.91$ & 0.99 & 0.054 & 0.49 \\
\hline Insulin (mU/L) & $7.97 \pm 4.85$ & $8.82 \pm 5.47$ & $0.85 \pm 6.15$ & $7.95 \pm 5.96$ & $10.40 \pm 9.31$ & $2.44 \pm 10.28$ & 0.11 & 0.53 & 0.44 \\
\hline HOMA_IR & $1.45 \pm 0.85$ & $1.52 \pm 1.21$ & $0.21 \pm 1.23$ & $1.66 \pm 1.11$ & $2.03 \pm 1.84$ & $0.50 \pm 2.03$ & 0.08 & 0.37 & 0.47 \\
\hline TG $(\mathrm{mg} / \mathrm{dl})$ & $98.59 \pm 34.10$ & $245.43 \pm 68.75^{*}$ & $146.83 \pm 59.16$ & $\begin{array}{l}97.22 \pm \\
49.94\end{array}$ & $\begin{array}{l}228.41 \pm \\
75.03^{*}\end{array}$ & $131.19 \pm 58.16$ & $\begin{array}{l}< \\
0.001\end{array}$ & 0.44 & 0.26 \\
\hline TC (mg/dl) & $153.78 \pm 29.05$ & $229.83 \pm 48.84^{*}$ & $76.05 \pm 38.110$ & $\begin{array}{l}158.22 \pm \\
36.58\end{array}$ & $\begin{array}{l}228.44 \pm \\
32.13^{*}\end{array}$ & $70.22 \pm 35$ & $\begin{array}{l}< \\
0.001\end{array}$ & 0.49 & 0.84 \\
\hline HDL (mg/dl) & $52.08 \pm 8.68$ & $62.08 \pm 10.61^{*}$ & $10 \pm 8.37$ & $\begin{array}{l}54.69 \pm \\
12.86\end{array}$ & $\begin{array}{l}64.22 \pm \\
15.78^{*}\end{array}$ & $9.52 \pm 11.39$ & $\begin{array}{l}< \\
0.001\end{array}$ & 0.36 & 0.84 \\
\hline LDL (mg/dl) & $81.98 \pm 20.93$ & $118.67 \pm 37.38^{*}$ & $36.68 \pm 29.93$ & $\begin{array}{l}84.08 \pm \\
26.06\end{array}$ & $\begin{array}{l}118.53 \pm \\
23.89^{*}\end{array}$ & $34.45 \pm 27.39$ & $\begin{array}{l}< \\
0.001\end{array}$ & 0.86 & 0.74 \\
\hline LDL/HDL-C & $1.58 \pm 0.36$ & $1.90 \pm 0.44^{*}$ & $0.31 \pm 0.44$ & $1.56 \pm 0.45$ & $1.91 \pm 0.46^{*}$ & $0.35 \pm 0.47$ & $\begin{array}{l}< \\
0.001\end{array}$ & 0.92 & 0.76 \\
\hline TC/HDL-C & $2.97 \pm 0.44$ & $3.71 \pm 0.49^{*}$ & $0.73 \pm 0.51$ & $2.93 \pm 0.55$ & $3.67 \pm 0.63^{*}$ & $0.73 \pm 0.52$ & $\begin{array}{l}< \\
0.001\end{array}$ & 0.68 & 0.99 \\
\hline Calcium (mg/dl) & $9.47 \pm 0.38$ & $8.97 \pm 0.37^{*}$ & $-0.5 \pm 0.41$ & $9.45 \pm 0.39$ & $9.01 \pm 0.32^{*}$ & $-0.43 \pm 0.45$ & $\begin{array}{l}< \\
0.001\end{array}$ & 0.88 & 0.51 \\
\hline Phosphate (mg/dl) & $4.37 \pm 0.45$ & $4.63 \pm 1.0$ & $0.26 \pm 1.06$ & $4.45 \pm 0.62$ & $4.45 \pm 0.49$ & $0.0 \pm 0.69$ & 0.21 & 0.67 & 0.21 \\
\hline iPTH (pg/ml) & $17.96 \pm 10.60$ & $13.78 \pm 7.05^{*}$ & $-4.18 \pm 7.5$ & $\begin{array}{l}23.51 \pm \\
15.77\end{array}$ & $15.15 \pm 7.68^{*}$ & $-8.36 \pm 14.17$ & $\begin{array}{l}< \\
0.001\end{array}$ & 0.11 & 0.13 \\
\hline MDA $(\mathrm{nmol} / \mathrm{mL})$ & $21.17 \pm 8.13$ & $17.6 \pm 8.7$ & $-1.64 \pm 10.42$ & $18.87 \pm 8.37$ & $18.17 \pm 8.07$ & $1.9 \pm 8.36$ & 0.52 & 0.46 & 0.26 \\
\hline $\begin{array}{l}\text { TAC ( } \mathrm{g} / \mathrm{dL} \text { BSA } \\
\text { equivalent) }\end{array}$ & $2.99 \pm 0.37$ & $2.79 \pm 0.58$ & $-0.19 \pm 0.67$ & $2.84 \pm 0.55$ & $2.78 \pm 0.45$ & $-0.06 \pm 0.62$ & 0.18 & 0.51 & 0.50 \\
\hline
\end{tabular}

${ }^{\mathrm{a}}$ All values are expressed as means $\pm \mathrm{SD}$ (standard deviation)

${ }^{2}$ Resulted from 1 -factor repeated measures ANOVA

*different from baseline, $p<0.05$

** difference of changes between groups, $P$-interaction $<0.05$

${ }^{\mathrm{b}}$ TimexGroup: Time means from the first to the last visit of intervention and group means comparison between the two groups of intervention 25(OH)D3 25-hydroxyvitamin D3, FBS fasting serum glucose, TC total cholesterol, TG triglycerides, LDL low-density lipoprotein, HDL high-density lipoprotein, iPTH intact parathyroid hormone, MDA malondialdehyde, TAC total antioxidant capacity, HOMA-IR homeostasis model assessment of insulin resistance

pregnancy were not different. Future studies with higher and safe doses of vitamin D supplementation may provide better explanations. The present study detected a significant reduction in maternal serum iPTH concentration in both groups at the end of pregnancy, and a negative correlation between serum concentrations of $25(\mathrm{OH}) \mathrm{D}$ and iPTH. In agreement with our study results, an interventional study of three treatment groups (400, 2000 or $4000 \mathrm{IU}$ vitamin D3/day) from 12 weeks of gestation until delivery, showed that the circulating PTH of African American group had inverse correlation with circulating 25(OH)D levels [59]. Okonofua et al., found an inverse correlation between serum 25(OH)D and PTH concentrations in the maternal serum but the inverse relationship disappeared when the ethnicity of women was considered separately [60].

We found no correlation between mothers' sera and cord blood concentrations of iPTH or cord blood

Table 3 Comparison of vitamin D status based on serum concentration of 25(OH)D between groups

\begin{tabular}{|c|c|c|c|c|c|c|c|}
\hline \multirow[t]{2}{*}{ Group } & \multicolumn{3}{|c|}{ Before intervention } & \multicolumn{3}{|c|}{ After intervention } & \multirow{2}{*}{$\begin{array}{l}p \\
\text { value }^{1}\end{array}$} \\
\hline & Deficient & Insufficient & Sufficient & Deficient & Insufficient & Sufficient & \\
\hline 1000 IU/day, n (\%) & $26(70.3)$ & $5(13.5)$ & $6(16.2)$ & $3(8.1)$ & $20(54.1)$ & $14(37.8)$ & 0.04 \\
\hline 2000 IU/day, n (\%) & $20(55.6)$ & $11(30.6)$ & $5(13.9)$ & $2(5.6)$ & $10(27.8)$ & $24(66.7)$ & \\
\hline Total, n (\%) & $46(63)$ & $16(21.9)$ & $11(15.1)$ & $5(6.8)$ & $30(41.1)$ & $38(52.1)$ & \\
\hline
\end{tabular}

${ }^{1}$ Denotes the significance of differences in the distribution of vitamin $D$ categories between the 2 groups (chi-square test)

Deficiency is defined as $<50 \mathrm{nmol} / \mathrm{L}$, insufficiency as $50-75 \mathrm{nmol} / \mathrm{L}$, and sufficiency as $>75 \mathrm{nmol} / \mathrm{L}$ 
Table 4 Cord blood biomarkers ${ }^{a}$

\begin{tabular}{|c|c|c|c|}
\hline $\begin{array}{l}\text { Group } \\
\text { Variable }\end{array}$ & $\begin{array}{l}1000 \mathrm{IU} / \mathrm{d} \\
\text { Group } \\
n=15\end{array}$ & $\begin{array}{l}2000 \mathrm{IU} / \mathrm{d} \\
\text { Group } \\
n=18\end{array}$ & $\begin{array}{l}p \\
\text { value }^{2}\end{array}$ \\
\hline $25(\mathrm{OH}) \mathrm{D}(\mathrm{nmol} / \mathrm{L})$ & $84.04 \pm 35.14$ & $89.0 \pm 25.27$ & 0.64 \\
\hline Cord blood 25(OH)D, n (\%) & & & 0.23 \\
\hline$<50 \mathrm{nmol} / \mathrm{l}$ & $3(20)$ & $0(0.0)$ & \\
\hline $50-75 \mathrm{nmol} / /$ & $4(26.7)$ & $7(38.9)$ & \\
\hline$>75 \mathrm{nmol} / \mathrm{l}$ & $8(53.3)$ & $11(61.1)$ & \\
\hline iPTH (pg/ml) & $4.53 \pm 2.82$ & $4.70 \pm 2.95$ & 0.87 \\
\hline MDA $(\mathrm{nmol} / \mathrm{mL})$ & $20.33 \pm 5.9$ & $20.55 \pm 9.43$ & 0.91 \\
\hline TAC (g/dL BSA equivalent) & $3.15 \pm 0.97$ & $3.36 \pm 0.91$ & 0.58 \\
\hline
\end{tabular}

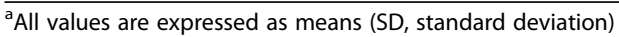

${ }^{2}$ Denotes the significance between groups differences (independent t-test) 25(OH)D3 25-hydroxyvitamin D3, iPTH intact parathyroid hormone, MDA malondialdehyde, TAC total antioxidant capacity

concentrations of $25(\mathrm{OH}) \mathrm{D}$ and iPTH. Similar to our results, Bowyer et al. showed no correlation between PTH in neonates and their mothers [61]. Considering the importance of minerals for fetus bone development, active transport of calcium occurs across the placenta which subsequently suppresses PTH secretion [62]. Hirota et al. have shown that there is a significantly higher level of the parathyroid hormonerelated protein (PTHrp) in umbilical venous blood than those in pregnant women at any trimester [63]. PTHrp has an important role in active transferring of calcium from mother to the fetus, possibly via changing the expression of calbindin-D $9 \mathrm{k}$ [64].

We found no significant changes in maternal serum concentration of MDA and TAC at the end of intervention in any of the two groups and also no significant between-group difference of these biomarkers in cord blood. Similar to our data the findings of a trial showed that vitamin D supplementation had no effect on OS biomarkers among pregnant women with GDM [55]. However, there are some evidence that support a positive association between TAC and vitamin D status [41, 65]. The findings of a systematic review of clinical trials among non-pregnant participants revealed that vitamin D only with doses of 100 , 000-200,000 IU/month could have beneficial effect on the OS parameters (decreases MDA levels and increases GSH and TAC levels) [23]. One of these mechanisms that explain the effect of vitamin $\mathrm{D}$ on OS biomarkers is the role of vitamin $\mathrm{D}$ on the expression of Nrf2 which in turn increases the production of anti-oxidant enzymes [66]. The lack of changes in OS biomarkers in the present study might, at least in part, be related to the applied doses of vitamin D. Therefore, further studies with different doses could clarify the role of vitamin D supplementation on the OS biomarkers in pregnant women.
One of the strength points of this randomized clinical trial is that vitamin D supplementation was started early in pregnancy and lasted until delivery. We also assessed dietary intake, physical activity level and sun exposure to find their possible confounding effects. Biochemical markers were measured in cord blood samples for better understanding of the effects of the intervention. Nonetheless, some limitations must be acknowledged. We did not have a placebo control group (no vitamin D intake via supplements including multivitamin) due to ethical issues. Yet, our participants were normo-glycemic and normo-lipidemic and this might hamper the possible effects of the intervention. However, this precaution was necessary as this trial was performed to help policymakers at the Iran Ministry of Health to decide on vitamin $\mathrm{D}$ supplementation during pregnancy for the whole country.

\section{Conclusions}

Supplementation with $2000 \mathrm{IU} / \mathrm{d}$ vitamin D had no more beneficial effects on the studied biomarkers of glycemic, lipidemic and OS status of the maternal and cord blood than with $1000 \mathrm{IU} / \mathrm{d}$. Nevertheless, supplementation with $2000 \mathrm{IU}$ a day, compared with $1000 \mathrm{IU} / \mathrm{d}$, was more effective in improving vitamin $\mathrm{D}$ status and lowering the occurrence of suboptimal circulating calcidiol concentrations during pregnancy.

\section{Abbreviations \\ ABTS: 2,2'-azino di-(3-ethylbenzthiazoline sulfonate); Ca: Calcium; \\ CV: Coefficient of variation; FBS: Fasting blood sugar; GDM: Gestational diabetes mellitus; HDL-C: High-density lipoprotein-cholesterol; HOMA- IR: Homeostatic model assessment of insulin resistance; $25(\mathrm{OH}) \mathrm{D}: 25-$ hydroxycalciferol; IOM: Institute of Medicine; iPTH: Intact parathyroid hormone; LDL-C: Low-density lipoprotein cholesterol; \\ MDA: Malondialdehyde; OS: Oxidative stress; SD: Standard deviation; SEM: Standard error of mean; TAC: Total antioxidant capacity; TC: Total cholesterol; TG: Triglyceride}

\section{Acknowledgements}

This paper represents part of data obtained from Soudabe Motamed's Ph.D. thesis in nutrition science. All laboratory bench works were done at Laboratory of Nutrition Research, NNFTRI. We would like to thank all pregnant women for their participation in this research.

\section{Authors' contributions}

TN and BN designed and supervised the study. BN involved in estimation of sample size and statistical analyses. All field works and most of laboratory analyses were performed by SM. TN and BN also helped in laboratory investigations. Criteria for subject selection were set with the aid of MK and MC who also made all arrangements in Akbarabadi Hospital. The preliminary manuscript was written by SM. The final manuscript was written by TN with the intellectual aid and comments of BH. All authors have read and approved the manuscript.

\section{Funding}

This research did not receive any specific grant from the university or any other funding agencies.

\section{Availability of data and materials}

The datasets used and/or analyzed during the current study are available from the corresponding author on reasonable request. 


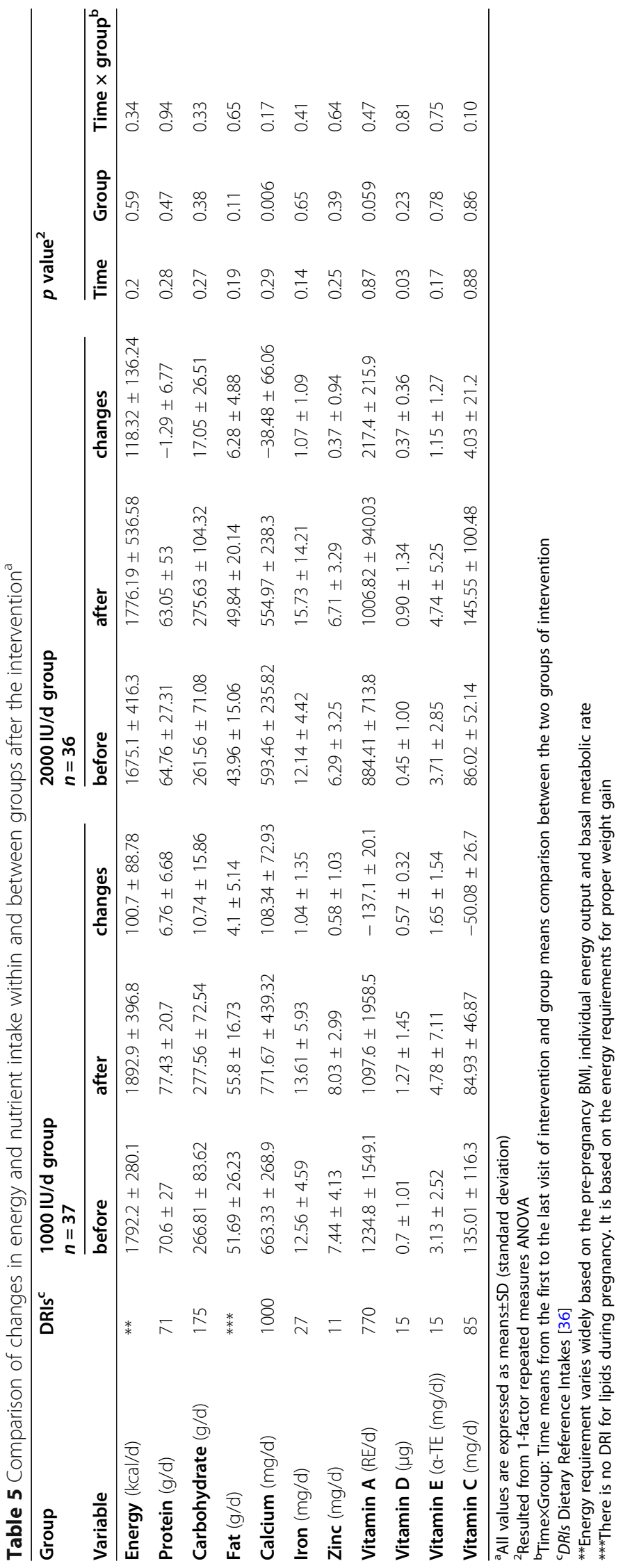




\section{Ethics approval and consent to participate}

The protocol of this study was approved by the Ethics Committee of Shahid Beheshti University of Medical Sciences (IR.SBMU.RETECH.1395.631). The consent form was signed by the participants. This trial is registered at clinicaltrials.gov (NCT03308487).

\section{Consent for publication}

Not applicable.

\section{Competing interests}

The authors declare that they have no competing interests.

\section{Author details}

'Department of Cellular and Molecular Nutrition, Shahid Beheshti University of Medical Sciences, Tehran, Iran. ${ }^{2}$ Laboratory of Nutrition Research, National Nutrition and Food Technology Research Institute and Faculty of Nutrition Sciences and Food Technology, Shahid Beheshti University of Medical Sciences, Hafezi St., Farahzadi Blvd., Shahrak Qods (Gharb), Tehran 1981619573, Iran. ${ }^{3}$ Department of Obstetrics \& Gynecology, Akbarabadi Teaching Hospital, Iran University of Medical Sciences, Tehran, Iran. ${ }^{4}$ Division of Neonatology, Department of Pediatrics, Medical University of South Carolina, Charleston, SC 29425, USA.

Received: 22 September 2019 Accepted: 5 October 2020 Published online: 14 October 2020

\section{References}

1. Sorenson RL, Brelje TC. Adaptation of islets of Langerhans to pregnancy: beta-cell growth, enhanced insulin secretion and the role of lactogenic hormones. Horm Metab Res. 1997;29(6):301-7 PubMed PMID: 9230352. Epub 1997/06/01. eng

2. Pusukuru R, Shenoi AS, Kumar Kyada P, Ghodke B, Mehta V, Bhuta K, et al. Evaluation of lipid profile in second and third trimester of pregnancy. J Clin Diagn Res. 2016;10(3):QC12-QC6.

3. Mankuta D, Elami-Suzin M, Elhayani A, Vinker S. Lipid profile in consecutive pregnancies. Lipids Health Dis. 2010;9:58 PubMed PMID: 20525387. Pubmed Central PMCID: PMC2904773. Epub 2010/06/08. eng.

4. Palacios C, Kostiuk LK, Peña-Rosas JP. Vitamin D supplementation for women during pregnancy. Cochrane Database Syst Rev. 2019;7(7): CD008873. https://doi.org/10.1002/14651858.CD008873.pub4.

5. Dovnik A, Mujezinović $F$. The association of vitamin $D$ levels with common pregnancy complications. Nutrients. 2018;10(7):867.

6. Al-Ajlan A, Al-Musharaf S, Fouda MA, Krishnaswamy S, Wani K, Aljohani NJ, et al. Lower vitamin D levels in Saudi pregnant women are associated with higher risk of developing GDM. BMC Pregnancy Childbirth. 2018;18(1):86 PubMed PMID: 29631547. Pubmed Central PMCID: PMC5891955. Epub 2018/04/11. eng.

7. Naseh A, Ashrafzadeh S, Rassi S. Prevalence of vitamin D deficiency in pregnant mothers in Tehran and investigating its association with serum glucose and insulin. J Matern Fetal Neonatal Med. 2018;31(17):2312-8 PubMed PMID: 28662591. Epub 2017/07/01. eng.

8. O'Brien E, O'Sullivan E, Kilbane M, Geraghty A, McKenna M, McAuliffe F. Season and vitamin D status are independently associated with glucose homeostasis in pregnancy. BJOG Int J Obstet Gynaecol. 2017;124:95 PubMed PMID: WOS:000398196800247.

9. Soytac Inancli I, Yayci E, Atacag T, Uncu M. Is maternal Vitamin D associated with gestational diabetes mellitus in pregnant women in Cyprus? Clin Exp Obstet Gynecol. 2016;43(6):840-3 PubMed PMID: 29944234. Epub 2016/01/ 01. eng.

10. Jamilian M, Karamali M, Taghizadeh M, Sharifi N, Jafari Z, Memarzadeh MR, et al. Vitamin D and evening primrose oil administration improve glycemia and lipid profiles in women with gestational diabetes. Lipids. 2016;51(3): 349-56.

11. Al-Ajlan A, Krishnaswamy S, Alokail MS, Aljohani NJ, Al-Serehi A, Sheshah E, et al. Vitamin D deficiency and dyslipidemia in early pregnancy. BMC Pregnancy Childbirth. 2015;15:314. https://doi.org/10. 1186/s12884-015-0751-5.

12. Wang L, Song Y, Manson JE, Pilz S, Marz W, Michaelsson K, et al. Circulating 25-hydroxy-vitamin $D$ and risk of cardiovascular disease: a meta-analysis of prospective studies. Circ Cardiovasc Qual Outcomes. 2012;5(6):819-29
PubMed PMID: 23149428. Pubmed Central PMCID: PMC3510675. Epub 2012/11/15. eng.

13. Swart KM, Lips P, Brouwer IA, Jorde R, Heymans MW, Grimnes G, et al. Effects of vitamin D supplementation on markers for cardiovascular disease and type 2 diabetes: an individual participant data meta-analysis of randomized controlled trials. Am J Clin Nutr. 2018;107(6):1043-53 PubMed PMID: 29868916. Epub 2018/06/06. eng.

14. Demer LL, Hsu JJ, Tintut Y. Steroid hormone Vitamin D: implications for cardiovascular disease. Circ Res. 2018;122(11):1576-85 PubMed PMID: 29798901. Epub 2018/05/26. eng.

15. Sears $C$. The relationship between 25 -hydroxy Vitamin D, parathyroid hormone and Glycemia during pregnancy and postpartum. Can J Diabetes. 2016;40(3):196-7.

16. Hemmingway A, O'Callaghan KM, Hennessy A, Hull GLJ, Cashman KD, Kiely ME. Interactions between Vitamin D status, Calcium Intake and Parathyroid Hormone Concentrations in Healthy White-Skinned Pregnant Women at Northern Latitude. Nutrients. 2018;10(7):916. https://doi.org/10.3390/ nu10070916.

17. Mannaerts D, Faes E, Cos P, Briede JJ, Gyselaers W, Cornette J, et al. Oxidative stress in healthy pregnancy and preeclampsia is linked to chronic inflammation, iron status and vascular function. PLoS One. 2018;13(9): e0202919.

18. Chiarello DI, Abad C, Rojas D, Toledo F, Vázquez CM, Mate A, et al. Oxidative stress: normal pregnancy versus preeclampsia. Biochimica et Biophysica Acta (BBA)-Molecular Basis of Disease. 2018.

19. Jauniaux E, Burton GJ. The role of oxidative stress in placental-related diseases of pregnancy. J Gynecol Obstet Biol Reprod (Paris). 2016;45(8):77585 PubMed PMID: 27212609. Epub 2016/10/23. Le role du stress oxydant dans les pathologies placentaires de la grossesse. fre.

20. Chiarello DI, Abad C, Rojas D, Toledo F, Vazquez CM, Mate A, et al. Oxidative stress: Normal pregnancy versus preeclampsia. Biochim Biophys Acta Mol basis Dis. 2018;24 PubMed PMID: 30590104. Epub 2018/12/28. eng.

21. Uberti F, Morsanuto V, Molinari C. Vitamin D in oxidative stress and diseases. A Critical Evaluation of Vitamin D-Basic Overview; 2017.

22. Wimalawansa SJ. Vitamin d deficiency: effects on oxidative stress, epigenetics, gene regulation, and aging. Biology. 2019;8(2):30,

23. Sepidarkish M, Farsi F, Akbari-Fakhrabadi M, Namazi N, Almasi-Hashiani A, Maleki $A$, et al. The effect of vitamin $D$ supplementation on oxidative stress parameters: a systematic review and meta-analysis of clinical trials. Pharmacol Res. 2018.

24. Nikooyeh B, Anari R, Neyestani TR. Vitamin D, oxidative stress, and diabetes: crossroads for new therapeutic approaches. In: Diabetes, oxidative stress and dietary antioxidants. London: Academic Press; 2020. p. 385-395.

25. Palacios C, Gonzalez L. Is vitamin D deficiency a major global public health problem? J Steroid Biochem Mol Biol. 2014;144 Pt A:138-45 PubMed PMID: 24239505. Pubmed Central PMCID: PMC4018438. Epub 2013/11/19. eng.

26. Saraf R, Morton SM, Camargo CA Jr, Grant CC. Global summary of maternal and newborn vitamin D status - a systematic review. Matern Child Nutr. 2016;12(4):647-68 PubMed PMID: 26373311. Epub 2015/09/17. eng.

27. Pirdehghan A, Vakili M, Dehghan R, Zare F. High prevalence of Vitamin D deficiency and adverse pregnancy outcomes in Yazd, a central province of Iran. J Reprod Infertil. 2016;17(1):34-8.

28. Abbasian M, Chaman R, Amiri M, Ajami ME, Jafari-Koshki T, Rohani $\mathrm{H}$, et al. Vitamin D Deficiency in Pregnant Women and Their Neonates. Global J Health Sci. 2016;8(9):54008 PubMed PMID: 27157170. Pubmed Central PMCI D: PMC5064090 publication of this paper. Epub 2016/05/10. eng.

29. Motamed S, Nikooyeh B, Kashanian M, Hollis BW, Neyestani TR. Efficacy of two different doses of oral vitamin $D$ supplementation on inflammatory biomarkers and maternal and neonatal outcomes. Matern Child Nutr. 2019; 15(4):e12867 PubMed PMID: 31250540. Epub 2019/06/30. eng.

30. Motamed S, Nikooyeh B, Kashanian M, Neyestani T. Evaluation of the efficacy of 1000 and $2000 \mathrm{IU} / \mathrm{d}$ vitamin D supplementation during pregnancy on maternal and newborn vitamin D status, metabolic, inflammatory and oxidative stress biomarkers, and maternal and neonatal outcomes: a study protocol. J Nutr Food Sci Res. 2018;5(3):3-10.

31. Yesiltepe Mutlu G, Ozsu E, Kalaca S, Yuksel A, Pehlevan Y, Cizmecioglu F, et al. Evaluation of vitamin $D$ supplementation doses during pregnancy in a population at high risk for deficiency. Horm Res Paediatr. 2014;81(6):402-8 PubMed PMID: 24714660. Epub 2014/04/10. eng.

32. Brustad M, Alsaker E, Engelsen O, Aksnes L, Lund E. Vitamin D status of middle-aged women at 65-71 degrees $\mathrm{N}$ in relation to dietary intake and 
exposure to ultraviolet radiation. Public Health Nutr. 2004;7(2):327-35 PubMed PMID: 15003141. Epub 2004/03/09. eng.

33. Vasheghani-Farahani A, Tahmasbi M, Asheri H, Ashraf H, Nedjat S, Kordi R. The Persian, last 7-day, long form of the international physical activity questionnaire: translation and validation study. Asian J Sports Med. 2011; 2(2):106-16 PubMed PMID: 22375226. Pubmed Central PMCID: PMC3289200. Epub 2012/03/01. eng.

34. Matthews DR, Hosker JP, Rudenski AS, Naylor BA, Treacher DF, Turner RC Homeostasis model assessment: insulin resistance and beta-cell function from fasting plasma glucose and insulin concentrations in man. Diabetologia. 1985; 28(7):412-9 PubMed PMID: 3899825. Epub 1985/07/01. eng.

35. Neyestani TR, Fereydouni Z, Hejazi S, Salehi-Nasab F, Nateghifard F, Maddah $M$, et al. Vitamin C status in Iranian children with acute lymphoblastic leukemia: evidence for increased utilization. J Pediatr Gastroenterol Nutr. 2007:45(1):141-4 PubMed PMID: 17592383. Epub 2007/06/27. eng.

36. Kominiarek MA, Rajan P. Nutrition recommendations in pregnancy and lactation. Med Clin North Am. 2016;100(6):1199-215 PubMed PMID: 27745590. Pubmed Central PMCID: PMC5104202. Epub 2016/10/18. eng.

37. Cooper C, Harvey NC, Bishop NJ, Kennedy S, Papageorghiou AT, Schoenmakers I, et al. Maternal gestational vitamin D supplementation and off spring bone health (MAVIDOS): a multicentre, double-blind, randomised placebo-controlled trial. Lancet Diabetes Endocrinol. 2016;4(5):393-402 PubMed PMID: WOS:000375107800020.

38. Zerofsky M, Jacoby B, Pedersen TL, Stephensen CB. Effects of a Randomized, Controlled Trial of Daily Vitamin D3 Supplementation During Pregnancy on Regulatory Immunity and Inflammation. FASEB J. 2016; PubMed PMID: WOS: 000406444700515

39. Hollis BW, Johnson D, Hulsey TC, Ebeling M, Wagner CL. Vitamin D supplementation during pregnancy: double-blind, randomized clinical trial of safety and effectiveness. J Bone Miner Res. 2011;26(10):2341-57.

40. Rodda CP, Benson JE, Vincent AJ, Whitehead CL, Polykov A, Vollenhoven B. Maternal Vitamin D supplementation during pregnancy prevents Vitamin D deficiency in the newborn: an open-label randomized controlled trial. Clin Endocrinol. 2015;83(3):363-8.

41. Zhang Q, Cheng Y, He M, Li T, Ma Z, Cheng H. Effect of various doses of vitamin D supplementation on pregnant women with gestational diabetes mellitus: a randomized controlled trial. Exp Ther Med. 2016;12(3):1889-95.

42. Casey C, McGinty A, Holmes VA, Hill AJ, Patterson CC, Young IS, et al. Maternal vitamin $D$ and markers of glycaemia during pregnancy in the Belfast Centre of the Hyperglycaemia and adverse pregnancy outcome study. Diabet Med. 2018;35(7):972-9 PubMed PMID: 29608221. Pubmed Central PMCID: PMC6013372. Epub 2018/04/03. eng.

43. Bal M, Ersoy GS, Demirtas O, Kurt S, Tasyurt A. Vitamin D deficiency in pregnancy is not associated with diabetes mellitus development in pregnant women at low risk for gestational diabetes. Turk J Obstet Gynecol. 2016;13(1):23-6 PubMed PMID: WOS:000376597400007.

44. Asemi Z, Foroozanfard F, Hashemi T, Bahmani F, Jamilian M, Esmaillzadeh A Calcium plus vitamin D supplementation affects glucose metabolism and lipid concentrations in overweight and obese vitamin D deficient women with polycystic ovary syndrome. Clin Nutr. 2015;34(4):586-92 PubMed PMID: 25300649. Epub 2014/10/11. eng.

45. Sergeev IN, Rhoten WB. 1,25-Dihydroxyvitamin D3 evokes oscillations of intracellular calcium in a pancreatic beta-cell line. Endocrinology. 1995; 136(7):2852-61 PubMed PMID: 7789310. Epub 1995/07/01. eng.

46. Grimes SB, Wild R. Effect of pregnancy on lipid metabolism and lipoprotein levels. In: De Groot L, Chrousos G, Dungan K, Feingold KR, Grossman A, Hershman JM, et al., editors. Endotext. South Dartmouth: MDText.com, Inc; 2000.

47. Ghodke B, Pusukuru R, Mehta V. Association of Lipid Profile in pregnancy with preeclampsia, gestational diabetes mellitus, and preterm delivery. Cureus. 2017:9(7):e1420 PubMed PMID: 28875093. Pubmed Central PMCID: PMC5580975. Epub 2017/09/07. eng.

48. Alvarez JJ, Montelongo A, Iglesias A, Lasuncion MA, Herrera E. Longitudina study on lipoprotein profile, high density lipoprotein subclass, and postheparin lipases during gestation in women. J Lipid Res. 1996;37(2):299308 PubMed PMID: 9026528. Epub 1996/02/01. eng.

49. Feingold KR, Wiley $\mathrm{T}$, Moser AH, Lear SR, Wiley MH. De novo cholesterogenesis in pregnancy. J Lab Clin Med. 1983;101(2):256-63 PubMed PMID: 6822762. Epub 1983/02/01. eng.

50. Belo L, Caslake M, Gaffney D, Santos-Silva A, Pereira-Leite L, Quintanilha A, et al. Changes in LDL size and HDL concentration in normal and preeclamptic pregnancies. Atherosclerosis. 2002;162(2):425-32 11996963. Epub 2002/05/09. eng.

51. Desoye G, Schweditsch MO, Pfeiffer KP, Zechner R, Kostner GM. Correlation of hormones with lipid and lipoprotein levels during normal pregnancy and postpartum. J Clin Endocrinol Metab. 1987;64(4):704-12 PubMed PMID: 3546352. Epub 1987/04/01. eng.

52. Larsson A, Palm M, Hansson LO, Axelsson O. Reference values for clinical chemistry tests during normal pregnancy. BJOG. 2008;115(7):874-81 PubMed PMID: 18485166. Epub 2008/05/20. eng.

53. Lepsch J, Eshriqui I, Farias DR, Vaz JS, Cunha Figueiredo AC, Adegboye AR, et al. Association between early pregnancy vitamin D status and changes in serum lipid profiles throughout pregnancy. Metabolism. 2017;70:85-97 PubMed PMID: 28403948. Epub 2017/04/14. eng.

54. Jin D, Yao MN, Yin WJ, Zhu P. The association of Vitamin D levels with lipid metabolism during pregnancy. Zhonghua Yu Fang Yi Xue Za Zhi. 2019; 53(6):628-32 PubMed PMID: 31177763. Epub 2019/06/11. chi.

55. Asemi Z, Hashemi T, Karamali M, Samimi M, Esmaillzadeh A. Effects of vitamin D supplementation on glucose metabolism, lipid concentrations, inflammation, and oxidative stress in gestational diabetes: a double-blind randomized controlled clinical trial. Am J Clin Nutr. 2013;98(6):1425-32 PubMed PMID: 24132976. Epub 2013/10/18. eng.

56. Yazdchi R, Gargari BP, Asghari-Jafarabadi M, Sahhaf F. Effects of vitamin D supplementation on metabolic indices and hs-CRP levels in gestational diabetes mellitus patients: a randomized, double-blinded, placebocontrolled clinical trial. Nutr Res Pract. 2016;10(3):328-35.

57. Karamali M, Beihaghi E, Mohammadi AA, Asemi Z. Effects of high-dose Vitamin D supplementation on metabolic status and pregnancy outcomes in pregnant women at risk for pre-eclampsia. Horm Metab Res. 2015;47(12): 867-72

58. Wang Y, Si S, Liu J, Wang Z, Jia H, Feng K, et al. The associations of serum lipids with Vitamin D status. PLoS One. 2016;11(10):e0165157 PubMed PMID: 27768777. Pubmed Central PMCID: PMC5074586. Epub 2016/10/22. eng.

59. Hollis BW, Wagner CL. Vitamin D requirements and supplementation during pregnancy. Curr Opin Endocrinol Diabetes Obes. 2011;18(6):371-5.

60. Okonofua F, Menon RK, Houlder S, Thomas M, Robinson D, O'Brien S, et al. Calcium, vitamin $D$ and parathyroid hormone relationships in pregnant Caucasian and Asian women and their neonates. Ann Clin Biochem. 1987; 24(1):22-8.

61. Bowyer L, Catling-Paull C, Diamond T, Homer C, Davis G, Craig ME. Vitamin D, PTH and calcium levels in pregnant women and their neonates. Clin Endocrinol. 2009;70(3):372-7.

62. Dror DK, King JC, Fung EB, van Loan MD, Gertz ER, Allen LH. Evidence of associations between feto-maternal vitamin D status, cord parathyroid hormone and bone-specific alkaline phosphatase, and newborn whole body bone mineral content. Nutrients. 2012;4(2):68-77.

63. Hirota Y, Anai T, Miyakawa I. Parathyroid hormone-related protein levels in maternal and cord blood. Am J Obstet Gynecol. 1997;177(3):702-6 PubMed PMID: 9322645. Epub 1997/10/10. eng.

64. Bond H, Dilworth MR, Baker B, Cowley E, Requena Jimenez A, Boyd RD, et al. Increased maternofetal calcium flux in parathyroid hormone-related protein-null mice. J Physiol. 2008;586(7):2015-25 PubMed PMID: 18258656. Pubmed Central PMCID: PMC2375733. Epub 2008/02/09. eng.

65. Gargari BP, Tabrizi FPF, Sadien B, Jafarabadi MA, Farzadi L. Vitamin D Status Is Related to Oxidative Stress But Not High-Sensitive C-Reactive Protein in Women with Pre-Eclampsia. Gynecol Obstet Investig. 2016;81(4):308-14 PubMed PMID: WOS:000380139700004.

66. Nakai K, Fujii H, Kono K, Goto S, Kitazawa R, Kitazawa S, et al. Vitamin D activates the Nrf2-Keap1 antioxidant pathway and ameliorates nephropathy in diabetic rats. Am J Hypertens. 2014;27(4):586-95.

\section{Publisher's Note}

Springer Nature remains neutral with regard to jurisdictional claims in published maps and institutional affiliations. 